\title{
Erratum: Cytoplasmic domain structures of Kir2.1 and Kir3.1 show sites for modulating gating and rectification
}

Scott Pegan, Christine Arrabit, Wei Zhou, Witek Kwiatkowski, Anthony Collins, Paul A Slesinger \& Senyon Choe

Nat. Neurosci. 8, 279-287 (2005)

Several sentences in this paper contained an error. On p. 283 in the left column, and on p. 284 in the left column, “Arg255” and “Arg259” should have read "Asp255" and "Asp259" respectively, in all cases.

\section{Erratum: The MAPK pathway and Egr-1 mediate stress-related behavioral} effects of glucocorticoids

Jean-Michel Revest, Francesco Di Blasi, Pierre Kitchener, Françoise Rougé-Pont, Aline Desmedt, Marc Turiault, François Tronche \& Pier Vincenzo Piazza

Nat. Neurosci. 8, 664-672 (2005)

A sentence in this paper contained an error. The fourth sentence of the abstract should have read as follows: "In the hippocampus of the wildtype mice after stress, as well as in the cell lines, activation of glucocorticoid receptors greatly increased the expression and enzymatic activity of proteins in the MAPK signaling pathway and led to an increase in the levels of both Egr-1 mRNA and protein."

\section{Erratum: Craving cocaine pERKs up the amygdala}

Yarimar Carrasquillo \& J David Sweatt

Nat. Neurosci. 8, 129-130 (2005)

Reference 1 contained incorrect page numbers. The corrected version should read as follows:

1. Lu, L. et al. Nat Neurosci. 8, 212-219 (2005). 